\title{
Znaczna poprawa kliniczna pacjenta leczonego sildenafilem z powodu nadciśnienia płucnego związanego z nadciśnieniem wrotnym
}

\author{
Significant clinical improvement in a patient with portopulmonary hypertension \\ treated with sildenafil
}

\begin{abstract}
Anna Daria Smukowska-Gorynia, Anna Olasińska-Wiśniewska, Katarzyna Małaczyńska-Rajpold, Magdalena Janus, Stanisław Jankiewicz, Anna Komosa, Aleksander Araszkiewicz, Tatiana Mularek-Kubzdela
\end{abstract}

I Klinika Kardiologii Uniwersytetu Medycznego im. Karola Marcinkiewicza w Poznaniu

\section{Streszczenie}

W pracy zaprezentowano przypadek 59-letniego pacjenta z nadciśnieniem wrotnym w przebiegu marskości wątroby, u którego doszło do rozwoju tętniczego nadciśnienia płucnego. Pacjenta zakwalifikowano do leczenia pierwszego rzutu lekiem sildenafil w dawce 20 mg 3 razy/dobę w ramach Programu Narodowego Funduszu Zdrowia Leczenia Tętniczego Nadciśnienia Płucnego. Po 6 miesiącach leczenia w badaniach kontrolnych stwierdzono znaczną poprawę kliniczną - zarówno wydolności fizycznej, jak i parametrów echokardiograficznych. Uzyskano także istotne obniżenie stężenia propeptydu natriuretycznego typu B.

Słowa kluczowe: nadciśnienie płucne związane z nadciśnieniem wrotnym, sildenafil, leczenie

(Folia Cardiologica 2015; 10, 5: 364-367)

\section{Wstęp}

Nadciśnienie płucne (PAH, pulmonary arterial hypertension) to stan, w którym w cewnikowaniu prawostronnym serca (RHC, right heart catheterization) stwierdza się średnie ciśnienie w tętnicy płucnej (mPAP, mean pulmonary arterial pressure) większe lub równe $25 \mathrm{~mm} \mathrm{Hg}$ i opór płucny (PVR, pulmonary vascular resistance) większy niż 240 dyn $\times \mathrm{s} \times \mathrm{cm}^{-5}$. Etiologia rozwoju PAH u pacjentów z nadciśnieniem wrotnym pozostaje niejasna. Uważa się, że jedną z przyczyn mogą być toksyny pochodzące z przewodu pokarmowego, które nie są eliminowane przez niewydolną wątrobę i mogą prowadzić do uszkodzenia śródbłonka naczyń płucnych. Inną przyczyną może być stan krążenia hiperkinetycznego z podwyższonym rzutem serca, który indukuje $\mathrm{PAH}$.

\section{Opis przypadku}

Mężczyzna w wieku 59 lat z objawami niewydolności serca w III klasie czynnościowej według Światowej Organizacji Zdrowia (WHO, World Health Organization) z marskością wątroby i nadciśnieniem wrotnym został przyjęty na oddział w celu kwalifikacji do leczenia PAH. W wywiadzie stwierdzono: chorobe alkoholową, żylaki przełyku leczone endoskopowo, nadczynność tarczycy leczoną radiojodem. W wykonanych badaniach wykazano cechy typowe dla PAH. W echokardiografii (ryc. 1, 2) uwidoczniono: powiększoną prawą komore (RV, right ventricle) (RV w projekcji przymostkowej w osi długiej $39 \mathrm{~mm}$, RV w projekcji koniuszkowej 4-jamowej $65 \mathrm{~mm}$, norma < $41 \mathrm{~mm}$ ) o obniżonej kurczliwości (wychylenie skurczowe pierścienia trójdzielnego [TAPSE, tricuspid annular plane

Adres do korespondencji: lek. Anna Daria Smukowska-Gorynia, I Klinika Kardiologii, Uniwersytet Medyczny im. Karola Marcinkiewicza, ul. Długa 1/2, 61-848 Poznań, e-mail: aniasmuk@wp.pl 


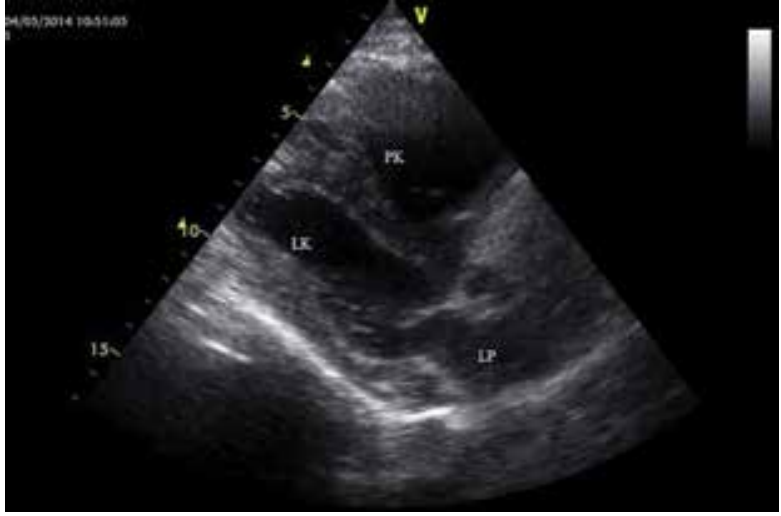

Rycina 1. Echokardiografia przed leczeniem sildenafilem. Projekcja przymostkowa w osi długiej - powiększona prawa komora (PK) (39 mm) uciska lewą komorę (LK), obecny paradoksalny ruch przegrody międzykomorowej w czasie rozkurczu; LP - lewy przedsionek

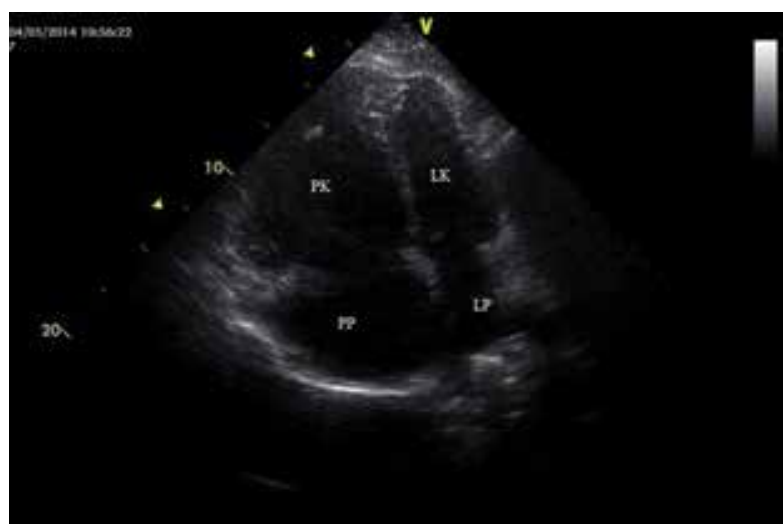

Rycina 2. Echokardiografia przed leczeniem sildenafilem. Projekcja koniuszkowa 4-jamowa - bardzo duża prawa komora (PK) $(65 \mathrm{~mm})$ i powiększony prawy przedsionek (PP), prawe jamy serca większe od lewych; LK - lewa komora; LP - lewy przedsionek

systolic excursion] $13 \mathrm{~mm}$, norma > $15 \mathrm{~mm}$, ale u większości zdrowych osób > 26 mm), uciskającą lewą komorę (wskaźnik ekscentryczności 1,65; norma < 1), istotna niedomykalność zastawki trójdzielnej (ryc. 3), ciśnienie skurczowe w prawej komorze (RVSP, right ventricular systolic pressure) $87 \mathrm{~mm} \mathrm{Hg}$ (ryc. 4), szeroką żyłę główną dolną o słabej ruchomości oddechowej, paradoksalny ruch przegrody międzykomorowej [1]. Elektrokardiografia wykazała: tachykardię zatokową 100/min, prawogram, blok prawej odnogi pęczka Hisa, cechy przerostu RV. Dystans w teście 6-minutowego chodu (6MWT, 6-minute walk test) wynosił $300 \mathrm{~m}$. W spiroergometriii $\mathrm{VO}_{2}$ max równe 13,9 ml/ $/ \mathrm{kg} / \mathrm{min}$. Cewnikowanie prawostronne serca ujawniło mPAP równe $50 \mathrm{~mm} \mathrm{Hg}$, PVR wynoszące 840 dyn $\times \mathrm{s} \times \mathrm{cm}^{-5}$ (10,5 j. Wooda) i ciśnienie zaklinowania tętniczek płucnych

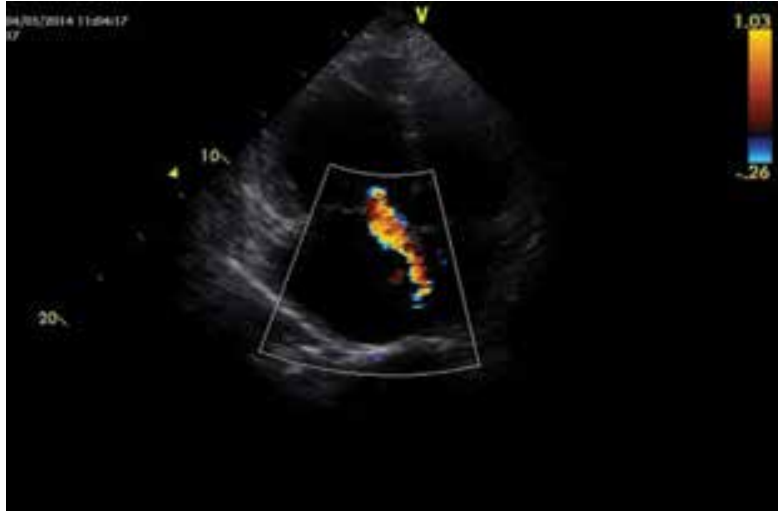

Rycina 3. Echokardiografia przed leczeniem sildenafilem. Projekcja koniuszkowa 4-jamowa - ciężka niedomykalność zastawki trójdzielnej (badanie metodą Dopplera znakowane kolorem)

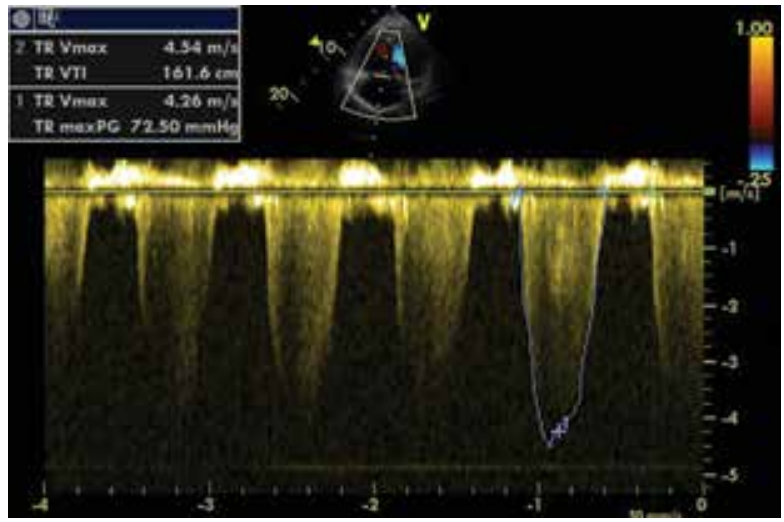

Rycina 4. Echokardiografia przed leczeniem sildenafilem. Projekcja koniuszkowa 4-jamowa - fala zwrotna przez zastawkę trójdzielną w badaniu metodą Dopplera fali ciągłej; wyliczone ciśnienie skurczowe w prawej komorze (RVSP, right ventricular systolic pressure) $87 \mathrm{~mm} \mathrm{Hg}$ (gradient maksymalny niedomykalności trójdzielnej $72 \mathrm{~mm} \mathrm{Hg}$ + oszacowane ciśnienie w prawym przedsionku $15 \mathrm{~mm} \mathrm{Hg}$ )

(PCWP, pulmonary capillary wedge pressure) równe $4 \mathrm{~mm} \mathrm{Hg}$. Stężenie propeptydu natriuretycznego typu B (proBNP, B-type natriuretic propeptide) wynosiło 3555 pg/ml (nor$\mathrm{ma}<125 \mathrm{pg} / \mathrm{ml}$ ). Rezonans magnetyczny serca ujawnił powiększoną RV z pogrubiałą ścianą wolną i uogólnioną hipokinezą i frakcję wyrzutową prawej komory wynosząco $27,4 \%$. Rozpoznano tętnicze nadciśnienie płucne przedwłośniczkowe [2] i wdrożono leczenie sildenafilem w dawce $20 \mathrm{mg} 3 \mathrm{razy} /$ dobę. W wykonanych badaniach kontrolnych po 6 miesiącach stwierdzono znaczną poprawę kliniczną. Pacjent był już w II klasie czynnościowej według WHO, dystans w 6MWT wydłużył się do $525 \mathrm{~m}, \mathrm{VO}_{2}$ max w spiroergometrii wzrosło do 19,1 ml/kg/min. Nastąpiła także istotna poprawa parametrów echokardiograficznych (ryc. 5, 6); stwierdzono: zmniejszenie RV (projekcja przymostkowa 


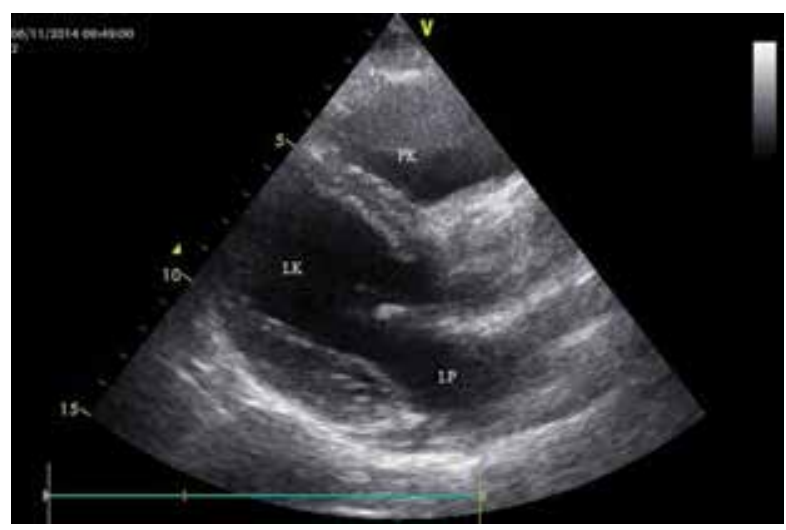

Rycina 5. Echokardiografia po 6 miesiącach leczenia sildenafilem. Projekcja przymostkowa w osi długiej - prawidłowy kształt lewej komory (LK), bez ruchu paradoksalnego przegrody międzykomorowej w czasie rozkurczu, zmniejszenie prawej komory (PK) do $31 \mathrm{~mm}$; LP - lewy przedsionek

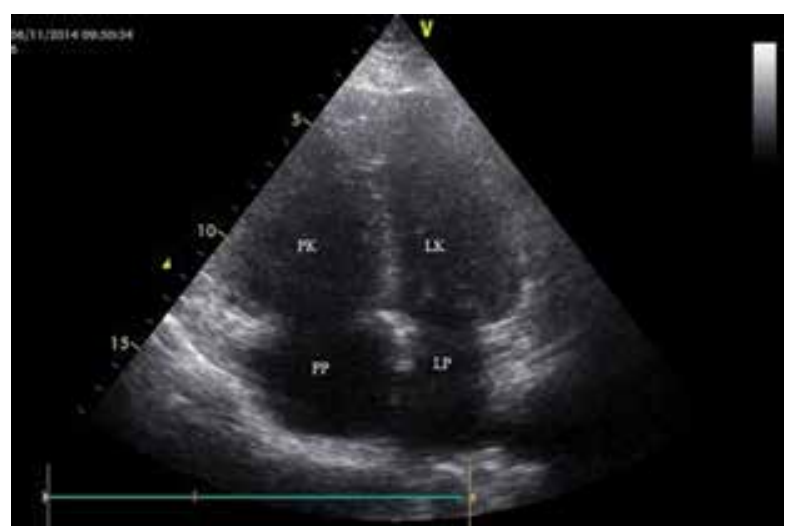

Rycina 6. Echokardiografia po 6 miesiącach leczenia sildenafilem. Projekcja koniuszkowa 4-jamowa - znaczne zmniejszenie prawej komory (PK) (41 mm), wymiar lewej komory (LK) zbliżony do wymiaru prawej; LP - lewy przedsionek; PP - prawy przedsionek

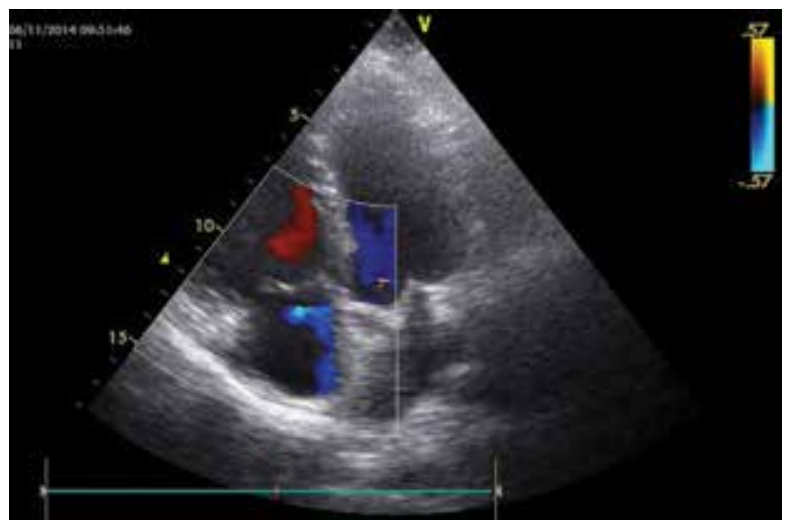

Rycina 7. Echokardiografia po 6 miesiącach leczenia sildenafilem. Projekcja koniuszkowa 4-jamowa - umiarkowana niedomykalność zastawki trójdzielnej (badanie doplerowskie znakowane kolorem)

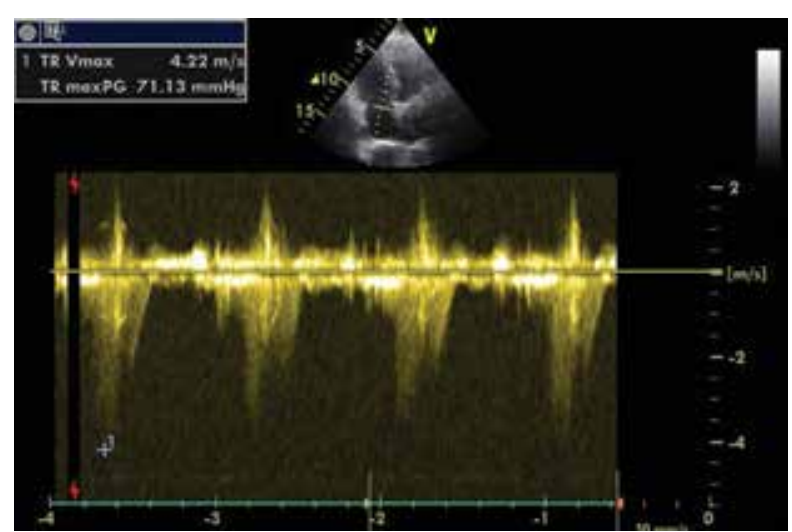

Rycina 8. Echokardiografia po 6 miesiącach leczenia sildenafilem. Projekcja koniuszkowa 4-jamowa - fala zwrotna przez zastawkę trójdzielną w badaniu metoda Dopplera fali ciągłej; wyliczone ciśnienie skurczowe w prawej komorze (RVSP, right ventricular systolic pressure) $75 \mathrm{~mm} \mathrm{Hg}$ (gradient maksymalny niedomykalności trójdzielnej $71 \mathrm{~mm} \mathrm{Hg}+$ oszacowane ciśnienie w prawym przedsionku $4 \mathrm{~mm} \mathrm{Hg}$ ). Zwraca uwagę znaczne zmniejszenie spektrum przepływu zwrotnego przez zastawkę trójdzielną w porównaniu $z$ badaniem sprzed leczenia

w osi długiej $31 \mathrm{~mm}$, projekcja koniuszkowa 4-jamowa $41 \mathrm{~mm}$, wskaźnik ekscentryczności 1,17) i niedomykalności zastawki trójdzielnej (ryc. 7), wartość RVSP równą $75 \mathrm{~mm} \mathrm{Hg}$ (ryc. 8), znaczną poprawę kurczliwości RV (TAPSE $20 \mathrm{~mm}$ ) oraz wąską, ruchomą oddechowo żyła główną dolną. Stężenie N-końcowego propeptydu natriuretycznego typu B (NT-proBNP, N-terminal B-type natriuretic propeptide) wynosiło $250 \mathrm{pg} / \mathrm{ml}$.

Częstość PAH u chorych z nadciśnieniem wrotnym wynosi 1-5\% [3]. Roczna śmiertelność pacjentów nieleczonych jest bardzo wysoka i mieści się w przedziale $24-60 \%$ [4]. U wszystkich wykazujących objawy pacjentów z chorobą wątroby oraz kandydatów do przeszczepienia wątroby należy wykonać badanie echokardiograficzne w kierunku PAH [2]. Następnie, w ośrodku referencyjnym, wykonuje się dalszą diagnostykę obejmującą RHC, a także inne badania pozwalające wykluczyć dominującą chorobę płuc, lewego serca lub etiologię zatorowo-zakrzepową. Obecnie, od stycznia 2014 roku, chorych z PAH i nadciśnieniem wrotnym można leczyć specyficznymi lekami - inhibitorami fosfodiesterazy 5 (sildenafil), antagonistami receptora endoteliny (bosentan, ambrisentan) oraz analogami prostacyklin (treprostinil, iloprost, epoprostenol) - w ramach Programu Leczenia Tętniczego Nadciśnienia Płucnego Narodowego Funduszu Zdrowia (NFZ). Leczeniem pierwszego rzutu PAH jest sildenafil podawany doustnie 3 razy/ /dobę; pozostałe leki stosuje się w terapii drugiego rzutu. W przypadku stwierdzenia pogorszenia stanu klinicznego należy wykonać powtórne badanie RHC. 0 pogorszeniu 
wskazującym na potrzebę zmiany terapii na drugi rzut świadczy spełnienie co najmniej dwóch z trzech poniższych parametrów hemodynamicznych w trakcie leczenia lekiem pierwszego rzutu: 1) wskaźnik sercowy mniejszy lub równy $2,4 \mathrm{l} / \mathrm{min} / \mathrm{m}^{2}, 2$ ) średnie ciśnienie w prawym przedsionku ponad $10 \mathrm{~mm} \mathrm{Hg}$, 3) saturacja mieszanej krwi żylnej mniejsza lub równa $65 \%$.

W literaturze pojawiają się coraz liczniejsze opisy przypadków swoistego leczenia PAH związanego z nadciśnieniem wrotnym jako pomostu do przeszczepienia wątroby [4] lub jako leczenia docelowego. U chorych, u których mPAP zostanie obniżone poniżej $35 \mathrm{~mm} \mathrm{Hg}$, śmiertelność okołooperacyjna jest niska. Natomiast u pacjentów z mPAP większym niż 50 mm Hg lub mPAP większym niż $35 \mathrm{~mm} \mathrm{Hg}$, przy jednoczesnym PVR przekraczającym 250 dyn $\times \mathrm{s} \times \mathrm{cm}^{-5}$, ryzyko okołooperacyjne jest bardzo duże i stanowi to przeciwwskazanie do przeszczepienia wątroby [5].

\section{Wnioski}

Nadciśnienie płucne rozwijające się u chorych z nadciśnieniem wrotnym jest poważnym stanem klinicznym i nieleczone ma złe rokowanie. U wykazujących objawy pacjentów z chorobami wątroby lub kandydatów do przeszczepienia wątroby należy wykonać, jako badanie przesiewowe, echokardiografię. Jeżeli jej wyniki wskazują na PAH, to chorego należy skierować do ośrodka referencyjnego w celu rozszerzenia diagnostyki, między innymi o RHC, i kwalifikacji do leczenia specyficznymi lekami. Pacjentów z mPAP wyższym lub równym $25 \mathrm{~mm} \mathrm{Hg}$, PVR większym niż 240 dyn $\times \mathrm{s} \times \mathrm{cm}^{-5}$ i PCWP mniejszym lub równym 15 należy włączyć do Programu Leczenia Tętniczego Nadciśnienia Płucnego NFZ.

\section{Konflikt interesów}

Autorzy deklarują brak konfliktu interesów

\section{Abstract}

We report a case of the 59-year-old men with portal hypertension and liver cirrhosis, who developed pulmonary arterial hypertension. The first line treatment with sildenafil $20 \mathrm{mg} 3$ times daily was introduced as part of a Polish National Treatment Program. At a 6-month follow-up we noticed a significant clinical improvement: the patient's exercise capacity and echocardiographic parameters were substantially better. In addition, the B-type natriuretic propeptide significantly decreased.

Key words: portopulmonary hypertension; sildenafil; treatment

(Folia Cardiologica 2015; 10, 5: 364-367)

\section{Piśmiennictwo}

1. Lang R.M., Badano L.P., Mor-Avi V. i wsp. Recommendations for Cardiac Chamber Quantification by Echocardiography in Adults: nn Update form the American Society of Echocardiography and the European Association of Cardiovascular Imaging. Eur. Heart J. Cardiovasc. Imaging 2015; 16: 233-271.

2. Galie N., Hoeper M., Humbert M. i wsp. Guidelines for the diagnosis and treatment of pulmonary hypertension. Eur. Heart J. 2009; 30: 2493-2537.

3. Krowka M.J., Swanson K.L., Frantz R.P. i wsp. Portopulmonary hypertension: results from a 10-year screening algorithm. Hepatology 2006; 44: 1502-1510.
4. Sag S., Yesilbursa D., Gullulu S. Treatment with a combination of bosentan and sildenafil allows for successful liver transplantation in a patient with portopulmonary hypertension. Turk. J. Gastroenterol. 2014; 25: 429-432.

5. Krowka M.J., Plevak D.J., Findlay J.Y. i wsp. Pulmonary hemodynamics and perioperative cardiopulmonary related mortality in patients with portopulmonary hypertension undergoing liver transplantation. Liver Transpl. 2000; 6: 443-50. 